(C) Elsevier/INRA

Note

\title{
Inheritance of coat and colour in the Griffon Bruxellois dog
}

\author{
R Robinson
}

St Stephens Nursery, St Stephens Road, London W13 8HB, UK

(Received 5 July 1993; accepted 12 November 1993)

Summary - The varieties of the Griffon Bruxellois dog consist of the colours black, red and black and tan, combined with either a rough or normal coat. Analysis of litter data reveals that the colours are produced by mutant alleles of the agouti locus, solid black $\left(A^{s}\right)$, dominant yellow $\left(A^{y}\right)$ and black and tan $\left(a^{t}\right)$, respectively. Rough coat is inherited as dominant to normal coat and may be attributed to the dominant wire hair mutant allele $W h$.

breed / canine colours / dog genetics

Résumé - Hérédité du pelage et de la couleur du chien Griffon bruxellois. Les variétés du chien Griffon bruxellois correspondent aux couleurs noir, rouge et noir et feu, combinées avec un pelage normal ou grossier. L'analyse de données de portées révèle que ces couleurs sont produites par des mutants au locus Agouti, noir uniforme $\left(\mathrm{A}^{\mathrm{s}}\right)$, jaune dominant $\left(\mathrm{A}^{\mathrm{y}}\right)$ et noir et feu $\left(\mathrm{a}^{\mathrm{t}}\right)$ respectivement. Le pelage grossier est dominant vis-à-vis du pelage normal et peut être attribué à l'allèle mutant poil dur $(W h)$.

pelage / coloration / génétique canine

\section{INTRODUCTION}

It is important to investigate the inheritance of coat type and colour varieties in individual breeds of dog. It is possible to make generalizations to explain the heredity in many breeds (Little, 1957; Robinson, 1990) but it is becoming apparent that certain breeds possess mutant alleles which are particular to the breed. From the earliest days of canine genetics, it has been known that alleles (1 dominant and 1 recessive) at 2 independent loci can produce a similar yellow or red coat colour (Little, 1957; Robinson, 1990). More recently, it has been discovered that 2 alleles at the same locus can produce a completely black coat (Willis, 1976; Carver, 1984). One can, therefore, no longer assume (Little, 1957) that black is always due to the same allele. Even more recently, it has been shown that the unique 
harlequin pattern of the Great Dane is genetically different from the merle pattern of other breeds, which it resembles phenotypically (Sponenberg, 1985; O'Sullivan and Robinson, 1989). Tweed is another colour which resembles merle, but which is genetically different and unique to the Australian Shepherd dog (Sponenberg and Lamoreux, 1985).

The present report describes an analysis of coat type and colour varieties in the Griffon Bruxellois, a toy breed of dog $(2.2-4.9 \mathrm{kgs})$, which was developed in Europe towards the end of the 19th century. The coat is bred for 2 types: that normal for the dog (known as smooth) and a wire hair (known as rough). The 2 most common colour varieties are the red, which is usually, if not always, accompanied by a variable black facial mask, and the solid black. A less common variety is the black and tan, where the whole body is black with tan-coloured markings. These comprise $2 \tan$ patches on the front of the chest, tan on the inside of the legs, and on the front of the legs from the carpal to the hock, together with 2 characteristic small tan spots above the eyes.

\section{MATERIALS AND METHODS}

The investigation proceeded by analysing coat quality and colour for pups in litters reported by breeders for the years 1991 and 1992. In total, 126 litters comprising 349 pups were examined; of these 49 litters provided evidence for segregation of mutant alleles as summarized in table I. The frequency of phenotypes representing the segregation of the alleles was estimated by the a priori method of Hogben (see Emery, 1976, p 40-42) on the assumption of near complete ascertainment. The validity of the method was checked by a parallel maximum likelihood estimation of the probability $(p)$ for the recessive phenotype within each mating type by the method of Haldane (see Emery, 1976, $\mathrm{p} 42-43$ ). The estimated values of $p$ are tabulated in the last column of table I. These biometric procedures effectively correct for the expectations as observed retrospectively, due to absence of segregation in small litters composed entirely of the dominant phenotype from heterozygous parents.

\section{RESULTS}

The heredity of the rough coat is that of segregation of a dominant mutant allele, as shown by the first 3 entries of table I. The observed frequencies for the intercross and backcross matings are fully consistent with expectation, as indicated by the non-significant values for $\chi^{2}$ and $p$ values in agreement with the expectations. The mating of smooth to smooth gave 10 smooth-coated pups.

The completely black colour behaved as a monogenic dominant to red, as evidenced by the 4th to 6 th entries of table I. The observed frequencies are in accord with expectation, as shown by the non-significant $\chi^{2}$ and $p$ values in agreement with the expectations. Furthermore, the mating of red to red gave 242 red pups.

The black and tan variety is relatively uncommon and this is reflected by the small amount of data on the segregation of the colour. However, it is apparent that the colour segregated as recessive to both black and red (7th and 8th entries of table I) and produces only black and tan pups when mated inter se (last entry of 
Table I. Segregation of the mutant alleles wire hair $(W h)$, dominant black $\left(A^{s}\right)$, dominant yellow $\left(A^{y}\right)$ and black and $\tan \left(a^{t}\right)$ in the Griffon Bruxellois dog.

\begin{tabular}{|c|c|c|c|c|c|c|c|}
\hline \multicolumn{2}{|l|}{ Mating } & \multicolumn{2}{|c|}{ Observed } & \multicolumn{2}{|c|}{ Expected } & \multirow[t]{2}{*}{$\chi^{2}$} & \multirow[t]{2}{*}{$p$} \\
\hline & & $W h$ & + & $W h$ & + & & \\
\hline$W h$ & $\times W h+$ & 41 & 23 & 38 & 26 & 0.57 & $0.15 \pm 0.07(0.25)$ \\
\hline$W h+$ & $x++$ & 34 & 49 & 33.4 & 49.6 & 0.02 & $0.49 \pm 0.07(0.50)$ \\
\hline++ & $\times++$ & $\overline{A^{s}}$ & 10 & $\overline{A^{s}}$ & 10 & & \\
\hline$A^{s} A^{y}$ & $\times A^{s} A^{y}$ & 10 & 6 & 10.1 & 5.9 & 0.01 & $0.26 \pm 0.14(0.25)$ \\
\hline$A^{s} A^{y}$ & $\times A^{y} A^{y}$ & 9 & 14 & 9.5 & 13.5 & 0.04 & $0.53 \pm 0.13(0.50)$ \\
\hline$A^{y} A^{y}$ & $\times A^{y} A^{y}$ & $\bar{A}$ & $\begin{array}{r}242 \\
a^{t}\end{array}$ & $\bar{A}$ & $242 a^{t}$ & & \\
\hline$A a^{t}$ & $\times A a^{t}$ & 5 & 6 & 5.9 & 5.1 & 0.31 & $0.41 \pm 0.19(0.25)$ \\
\hline$A a^{t}$ & $\times a^{t} a^{t}$ & 3 & 4 & 2.5 & 4.5 & 0.13 & $0.36 \pm 0.26(0.50)$ \\
\hline$a^{t} a^{t}$ & $\times a^{t} a^{t}$ & - & 21 & - & 21 & & \\
\hline
\end{tabular}

Segregation $\chi^{2}$ has 1 degree of freedom (each of which is non-significant); $p$ : probability of the recessive phenotype \pm se with expected value in brackets. Symbol $A$ of the last 3 matings represents either of the agouti alleles $A^{s}$ or $A^{y}$ (see text).

table I). In table I, the litters from black and red parents that gave black and tan pups are grouped since there were so few of each. The legitimacy for this is given in the discussion. The black and tan colour behaves as a recessive to both black and red.

The mutant allele for chocolate colour is present in the breed at a low frequency. Two litters from black parents gave 7 black and 3 chocolate pups. This indicates monogenic recessive heredity and is in keeping with breeding information on the colour for other breeds of dog (Little, 1957; Robinson, 1990).

\section{DISCUSSION}

A general exposition of the nature and heredity of coat and colour mutant alleles for the dog may be found in Little (1957) and Robinson (1990).

The monogenic inheritance of the rough coat found in the Griffon Bruxellois conforms with the dominant heredity of the trait in several other breeds (Robinson, 1990). On the principle of economy of hypothesis, the same mutant allele may be involved, with the proviso that this may not necessarily be the case. The symbol Wh denotes the wire hair allele (Robinson, 1990).

To comprehend the nature of the colour varieties for the Griffon Bruxellois, it is wise to review the relevant genetics of the dog. The solid black colour may be produced by either of 2 alleles at the agouti locus. These are: 1) dominant black $A^{s}$; and 2) non-agouti or recessive black $a$. The red colour may be produced by either of 2 alleles: 1) dominant yellow $A^{y}$, also at the agouti locus; and 2) non-extension of black or recessive yellow $e$ at the extension locus. It is relevant that the $e$ is epistatic to the agouti alleles. Black and tan is produced by an allele $a^{t}$, at the agouti locus. The dominance relations of the agouti alleles are $A^{s}>A^{y}>a^{t}>a$. 
The solid black variety of the Griffon Bruxellois is due to the $A^{s}$ allele since, if it were due to the $a$ allele, it would be incapable of segregating red and black and $\tan$. The red variety is due to the $A^{y}$ allele since if it were due to the $e$ allele it would be incapable of segregating black and tan. Moreover, there is another reason for excluding the $e$ allele. The red variety habitually has a black mask, which can manifest in conjunction with $A^{y}$ but not with $e$.

The black and tan variety is produced by the $a^{t}$ since the colour segregated from mating of both black to black and from red to red, which is completely consistent with its position in the agouti series as the most recessive allele.

Accordingly, the genotypes of the colour varieties of the Griffon Bruxellois may be written as: solid black $A^{s}$-, red $A^{y}$ - and black and $\tan a^{t} a^{t}$, where the dash indicates possible homozygosity or heterozygosity of the allele. All of the colour varieties may be bred with or without the rough coat allele $W h$.

The investigation provided some information on the distribution of litter sizes for the breed. The range varied from 1 to 6 pups per litter, with a mean of $2.71 \pm 0.13$ per litter. The frequency distribution was notably skewed towards the smaller litters.

\section{ACKNOWLEDGMENTS}

I thank the many breeders who provided details of litters and particularly Mrs P Sturman, archivist of the Griffon Bruxellois Club, who collected the information that formed the basis of this study.

\section{REFERENCES}

Carver EA (1984) Coat colour genetics of the German shepherd dog. $J$ Hered 75, 247-253

Emery AEH (1976) Methodology in Medical Genetics. Churchill Livingstone, Edinburgh

Little CC (1957) Inheritance of Coat Colour in Dogs. Cornell University Press, NY O'Sullivan N, Robinson R (1989) Harlequin colour in the Great Dane dog. Genetica $78,215-218$

Robinson R (1990) Genetics for Dog Breeders. Pergamon Press, Oxford Sponenberg DP (1985) Inheritance of harlequin color in Great Danes. J Hered 76, 224-225

Sponenberg DP, Lamoreux ML (1985) Inheritance of tweed: a modification of merle in the Australian shepherd dog. $J$ Hered 79, 303-304

Willis MB (1976) The German Shepherd Dog. K \& R Books, Queniborough 